\title{
Prospective evaluation of visual outcomes with three presbyopia-correcting intraocular lenses following cataract surgery
}

This article was published in the following Dove Press journal:

Clinical Ophthalmology

16 September 2013

Number of times this article has been viewed

\section{RE Ang ${ }^{1,2}$ \\ GA Martinez ${ }^{2,3}$ \\ EM Cruz' \\ AA Tiongson' \\ AG Dela Cruz'}

'Asian Eye Institute, Makati City, Philippines; ${ }^{2}$ Cardinal Santos Medical Center, San Juan City, Philippines;

${ }^{3}$ Pasig City General Hospital,

Pasig City, Philippines
Correspondence: Robert E Ang Asian Eye Institute, 9th Floor, PHINMA Plaza, Rockwell Center, Makati City,

Philippines 1200

Tel +6328973925

Email angbobby@hotmail.com
Purpose: To compare the visual acuity and quality of vision achieved with three widely-used intraocular lenses (IOLs) in subjects with bilateral cataracts.

Patients and methods: This three-arm, parallel, prospective, partially masked, singlesurgeon study randomized 78 subjects to receive bilateral Crystalens ${ }^{\circledR}$ Advanced Optics (AO) accommodating IOLs, AcrySof ${ }^{\circledR}$ IQ ReSTOR ${ }^{\circledR}+3.0$ multifocal IOLs, or TECNIS ${ }^{\circledR}$ Multifocal IOLs. Examinations were assessed through days 120 to 180.

Results: The Crystalens AO group had statistically significantly better monocular and binocular, high-contrast (HC) and low-contrast (LC) uncorrected intermediate visual acuity, HC and LC distance-corrected intermediate visual acuity, and significantly fewer monocular and binocular halos and starbursts than did the ReSTOR and TECNIS groups. Monocular and binocular, HC and LC uncorrected near visual acuity exhibited no significant differences among the three lenses. For monocular and binocular $\mathrm{HC}$ distance-corrected near visual acuity, the Crystalens AO performed significantly better than the TECNIS and was not significantly different from the ReSTOR. For monocular and binocular LC distance-corrected near visual acuity, the Crystalens AO performed significantly better than both the ReSTOR and the TECNIS. Contrast sensitivity was clinically similar between groups. The Crystalens AO produced statistically fewer halos and starbursts.

Conclusion: All three IOLs had excellent uncorrected acuity results at all distances and had good safety, confirming the established safety and effectiveness of these IOLs. Distance and near vision were similar between all three IOLs, and the Crystalens AO provided statistically significantly better intermediate vision.

Keywords: Crystalens, accommodating, AcrySof, TECNIS, multifocal

\section{Introduction}

Accommodating intraocular lenses (IOLs) are designed to replicate physiologic accommodation by changing the refractive power of the eye through contraction of the ciliary muscle, change in vitreous pressure, or reduction in diameter of the capsular bag. ${ }^{1,2}$ Accommodating IOLs have a single point of focus; light is not distributed between multiple images. The accommodating lens produces functional near vision and high quality intermediate and distance vision. 1,3,4

Multifocal IOLs are designed with refractive and diffractive optical properties that divide light into more than one focal point to provide near and distance vision. As a consequence, each primary image produced by the multifocal IOL has less contrast and more blurring than a monofocal IOL. ${ }^{5,6}$ This results in decreased sharpness of vision and contrast sensitivity, particularly under poor illumination. ${ }^{7-9}$ Intermediate vision 
may be affected by poor image sharpness ${ }^{9}$ because of the innate IOL design.

Currently, the only accommodating IOL approved by the US Food and Drug Administration (FDA) is the Crystalens $^{\circledR}$ advanced Optics (AO) accommodating IOL (Bausch \& Lomb Inc., Rochester, NY, USA). Two multifocal IOLs that are widely used in the US are the AcrySof ${ }^{\circledR}$ IQ ReSTOR $^{\circledR}+3.0$ IOL (Alcon Laboratories, Inc., Fort Worth, TX, USA) and the TECNIS ${ }^{\circledR}$ Multifocal IOL (Abbott Medical Optics, Inc., Santa Ana, CA, USA). The clinical outcomes achieved with these IOLs have not been compared previously. Hence, the purpose of this randomized study was to compare the visual acuity and quality of vision achieved with these IOLs.

\section{Material and methods Study design and subjects}

This three-arm, parallel, prospective, randomized, partially masked, single-surgeon study was conducted at the Asian Eye Institute, Makati City, Philippines. Following a baseline preoperative examination, subjects were randomly assigned (based upon a 1:1:1 sequential scheme with block randomization to balance treatment groups over time) to receive the bilateral Crystalens AO IOLs, the Acrysof IQ ReSTOR +3.0 IOLs, or the TECNIS Multifocal IOLs. The patients were masked as to which IOLs they were receiving.

The study included consecutive subjects who met the following criteria: $\geq 40$ years; age-related bilateral cataracts; spherical lens power from 10.00 diopters (D) to $33.00 \mathrm{D}$; potential for corrected distance visual acuity (CDVA) of 20/32 or better; scotopic $\left(3 \mathrm{~cd} / \mathrm{m}^{2}\right)$ pupil diameter $\geq 5.0 \mathrm{~mm}$; intact centered capsulorhexis, intact posterior capsule, no zonular rupture; and $\leq 1.25 \mathrm{D}$ of preoperative corneal astigmatism. Exclusion criteria were previous corneal pathology that could potentially affect topography; degenerative visual disorders causing potential losses of 20/32 or worse; increased risk of zonular rupture; ocular inflammation or corneal edema; uncontrolled glaucoma; previous retinal detachment; significant diabetic retinopathy, previous corneal surgery, microphthalmos, aniridia, amblyopia, or iris neovascularization. All subjects provided written informed consent after review of the risks and benefits. The study adhered to the Declaration of Helsinki and was approved by the Asian Eye Institute Ethics Review Committee.

\section{Intraocular lenses}

The Crystalens AO (models AT-50AO and AT-52AO) silicone multi-piece accommodating IOL is a modified plate haptic lens. ${ }^{10}$ The ReSTOR +3.0 (model SN6AD1) aspheric multifocal IOL combines the functions of an apodized diffractive region and a refractive region. ${ }^{11}$ The TECNIS Multifocal foldable hydrophobic acrylic IOL (model ZMA00) is an ultraviolet absorbing posterior chamber IOL. ${ }^{12}$

\section{Presurgical and surgical technique}

The Sanders-Retzlaff-Kraff theoretical prediction formula ${ }^{13}$ was used for the biometrical calculation. Based on measurements, surgical technique, experience, and postoperative results, the surgeon used the following personalized A-constants: 119.1 for the Crystalens AO, 119.5 for the ReSTOR, and 119.3 for the TECNIS IOL. The first eyes of the multifocal IOL groups were targeted for emmetropia, and the first eyes of the Crystalens AO group were targeted for $-0.50 \mathrm{D}$.

All surgeries were performed using a standard sutureless microincision phacoemulsification technique. A temporal clear corneal incision was made followed by $5.0 \mathrm{~mm}$ round continuous curvilinear capsulorhexis (CCC) in the ReSTOR and TECNIS groups, and $6.0 \mathrm{~mm}$ round $\mathrm{CCC}$ in the Crystalens AO group. The IOLs were implanted into the capsular bag after capsule polishing. The Crystalens AO was rotated to ensure that the haptics were properly located within the capsular bag, and the long axis was oriented along the superior-inferior axis. The orientation for the multifocal IOLs was nonspecific.

\section{Examination methods}

Monocular and binocular examinations were performed at postoperative days 1 to 2 (Visit 1), days 7 to 14 (Visit 2), days 30 to 60 (Visit 3), and days 120 to 180 (Visit 4). Assessments included manifest refraction; high-contrast (HC) and lowcontrast (LC) uncorrected distance visual acuity (HC-UDVA and LC-UDVA respectively); HC and LC uncorrected intermediate visual acuity (HC-UIVA and LC-UIVA respectively); $\mathrm{HC}$ and LC uncorrected near visual acuity (HC-UNVA and LC-UNVA respectively); HC-CDVA, LC-CDVA; HC and LC distance-corrected intermediate visual acuity (HC-DCIVA and LC-DCIVA respectively); and HC and LC distance-corrected near visual acuity (HC-DCNVA and LC-DCNVA respectively). Visual acuities (VAs) were recorded using the Optec 6500/6500P Vision Tester (Stereo Optical Co, Chicago, IL, USA). The tester was calibrated for distance vision at $6 \mathrm{~m}$, near vision at $40 \mathrm{~cm}$, and intermediate vision at $80 \mathrm{~cm}$. Contrast sensitivity with and without glare (primary endpoint) was evaluated using the Optec 6500/6500P Vision Tester under mesopic conditions. Subjective halos and starbursts were assessed in 
undilated pupils using a glarometer (Gulden Ophthalmics, Inc, Elkins Park, PA, USA) on 5-point integer scale. Adverse events were recorded and compared to cumulative and persistent FDA defined historical control rates. ${ }^{14}$ Defocus was tested using manifest refraction and an Early Treatment Diabetic Retinopathy Study (ETDRS) chart at $4.0 \mathrm{~m}$ under mesopic conditions (approximately $60-80 \mathrm{~cd} / \mathrm{m}^{2}$ ). Slit lamp evaluations included corneal stromal edema and anterior chamber aqueous cell and flare. Intraocular pressure (IOP) was measured with a Goldmann applanation tonometer. Pupil size under mesopic (3 $\mathrm{cd} / \mathrm{m}^{2}$ ) and photopic conditions was measured using a pupillometer (Neuroptics Inc., Irvine, CA, USA). A color test was performed with the Farnsworth Munsell 100 Hue test (FMTS Farbmesstechnik Schröder, Velbert, Germany). Aberrometry of the accommodating IOL (Crystalens AO) was measured using the iTrace (Tracey Technologies, Houston, TX, USA) aberrometer, which uses ray tracing technology to measure the refractive power of the eye as well as the dioptric power change of the eye during accommodation. The iTrace aberrometer is designed to assist in objectively determining the accommodative amplitude. Using the iTrace aberrometer, high and low order aberrations were measured by capturing wavefront analysis at far $(6 \mathrm{~m})$ and near $(40 \mathrm{~cm})$ distance readings to determine accommodative abilities.

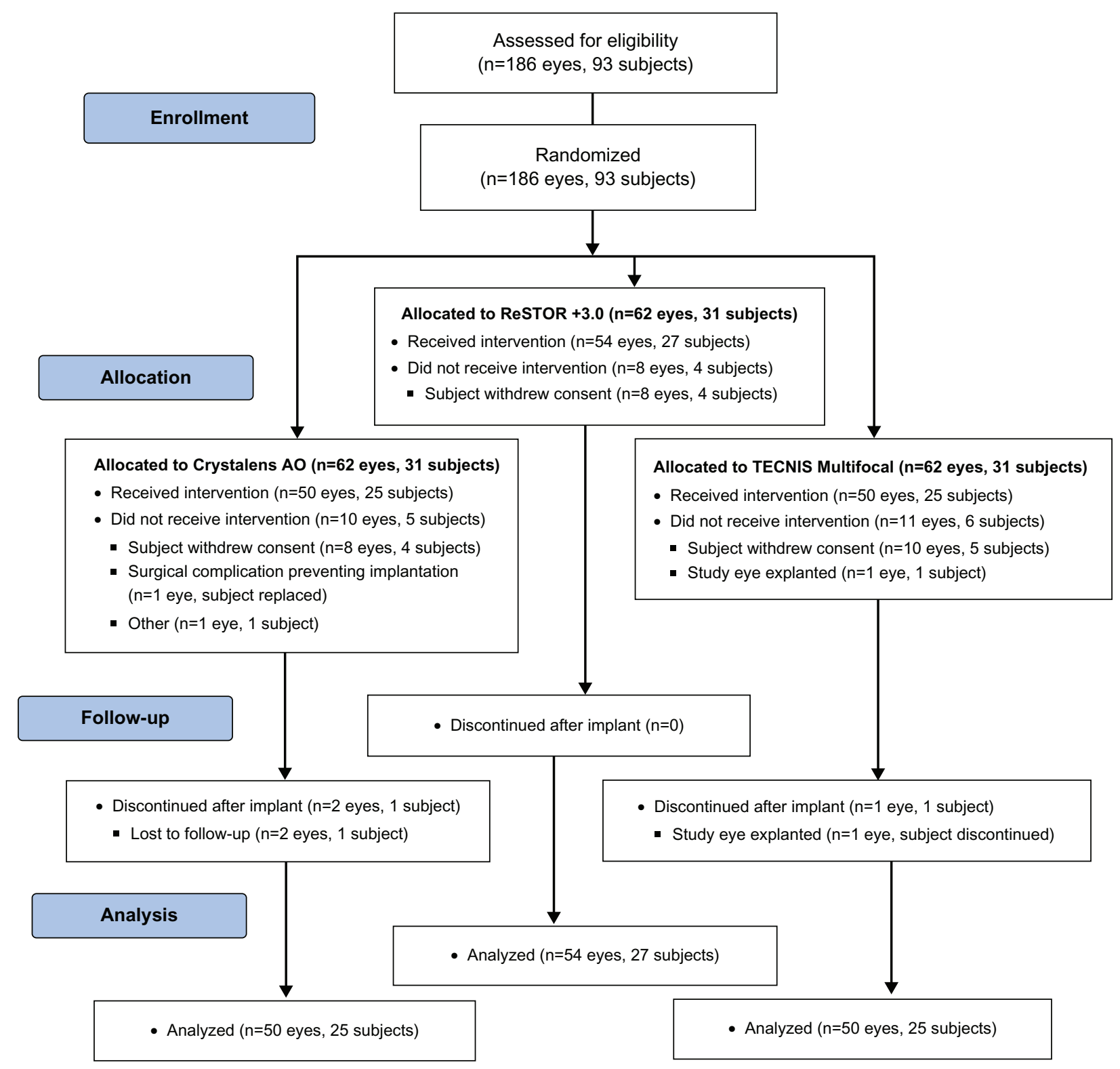

Figure I Participant flow diagram.

Notes: ReSTOR (Bausch \& Lomb, Inc.; Rochester, NY, USA), TECNIS (Abbott Medical Optics, Inc.; Santa Ana, CA, USA ), Crystalens AO (Bausch \& Lomb Inc.; Rochester, NY, USA).

Abbreviations: $n$, number of subjects; AO, Advanced Optics. 


\section{Statistical analysis}

A sample size of 32 eyes (16 subjects) in each group provides $90 \%$ power to detect a difference in means with a 0.0025 two-sided alpha risk level. Statistical analyses included all subjects who underwent surgery for bilateral implantation. Continuous monocular endpoints were evaluated with pairwise comparisons by visit using mixed models, including fixed effect of lens type and random effect of subject, nested within treatment groups. Continuous or ordinal binocular (or subject-level) endpoints were evaluated with pair-wise comparisons by visit using asymptotic Mann-Whitney rank sum tests. Ordinal monocular endpoints were compared by visit using generalized estimating equations assuming multinomial distributions and cumulative logit link functions. Binary monocular endpoints were evaluated with pair-wise comparisons by visit using generalized estimating equations assuming binary distributions and logit link functions. Binary binocular endpoints were evaluated with pair-wise comparisons by visit using two-sided Fisher's exact tests. A clinically significant difference in mean log contrast sensitivity was set at 0.3 . A Bonferroni correction was conducted where relevant. Means and standard deviations are presented; statistical significance was set at $P<0.05$.

\section{Results}

\section{Disposition and baseline characteristics}

Subject disposition is reported in Figure 1. In all, 93 subjects were randomly assigned to the three treatment arms (31 subjects/ group). The majority of subjects were women: $74 \%(23 / 31)$ in the Crystalens AO group, 81\% (25/31) in the ReSTOR group, and $71 \%(22 / 31)$ in the TECNIS group. The mean age for all three groups was 64 to 65 years (range: $40-80$ years).

\section{Manifest refraction and aberrometry}

Manifest sphere, cylinder, and manifest refractive spherical equivalent (MRSE) are shown in Table 1 for all visits. Refractive outcomes were as predicted for all groups and stable up to 180 days. At Visit 4, the manifest sphere and spherical equivalent for the Crystalens AO group was significantly different from that of the ReSTOR $(P=0.018$ and $P=0.047$, respectively) and the TECNIS groups ( $P=0.019$ and $P=0.018$, respectively). Outcomes between the ReSTOR and TECNIS groups were not statistically different.

The Crystalens AO group underwent objective evaluation of accommodation by capturing the change in the patient's wavefront and refraction via the iTrace aberrometer. The near and distance readings were compared to determine the
Table I Refractive outcomes

\begin{tabular}{|c|c|c|c|}
\hline & Crystalens AO & ReSTOR +3.0 & $\begin{array}{l}\text { TECNIS } \\
\text { Multifocal }\end{array}$ \\
\hline \multicolumn{4}{|c|}{ Manifest sphere (D) } \\
\hline Preoperative & $(n=53)$ & $(n=54)$ & $(n=5 I)$ \\
\hline Mean \pm SD & $0.759 \pm 2.60$ & $0.532 \pm 2.92$ & $1.245 \pm 1.88$ \\
\hline Visit 2 & $(n=52)$ & $(n=54)$ & $(n=5 I)$ \\
\hline Mean \pm SD & $-0.096 \pm 0.520 * *$ & $0.171 \pm 0.394$ & $0.299 \pm 0.367$ \\
\hline Visit 3 & $(n=52)$ & $(n=54)$ & $(\mathrm{n}=50)$ \\
\hline Mean \pm SD & $-0.072 \pm 0.527^{\dagger}$ & $0.148 \pm 0.508$ & $0.255 \pm 0.359$ \\
\hline Visit 4 & $(n=50)$ & $(n=54)$ & $(n=50)$ \\
\hline Mean \pm SD & $-0.065 \pm 0.492^{*, \dagger}$ & $0.218 \pm 0.491$ & $0.195 \pm 0.402$ \\
\hline \multicolumn{4}{|c|}{ Manifest cylinder (D) } \\
\hline Preoperative & $(n=53)$ & $(n=54)$ & $(n=5 I)$ \\
\hline Mean \pm SD & $-0.750 \pm 0.537$ & $-0.718 \pm 0.500$ & $-0.701 \pm 0.594$ \\
\hline Visit 2 & $(n=52)$ & $(n=54)$ & $(n=5 I)$ \\
\hline Mean \pm SD & $-0.572 \pm 0.348$ & $-0.537 \pm 0.355$ & $-0.574 \pm 0.340$ \\
\hline Visit 3 & $(n=52)$ & $(n=54)$ & $(n=50)$ \\
\hline Mean \pm SD & $-0.577 \pm 0.338$ & $-0.630 \pm 0.397$ & $-0.550 \pm 0.350$ \\
\hline Visit 4 & $(n=50)$ & $(n=54)$ & $(n=50)$ \\
\hline Mean \pm SD & $-0.555 \pm 0.321$ & $-0.667 \pm 0.426$ & $-0.530 \pm 0.393$ \\
\hline \multicolumn{4}{|l|}{ MRSE (D) } \\
\hline Preoperative & $(n=53)$ & $(n=54)$ & $(n=5 I)$ \\
\hline Mean \pm SD & $0.384 \pm 2.600$ & $0.174 \pm 3.011$ & $0.895 \pm 1.978$ \\
\hline Visit 2 & $(n=52)$ & $(n=54)$ & $(n=5 I)$ \\
\hline Mean \pm SD & $-0.382 \pm 0.478 * *,+\dagger$ & $-0.097 \pm 0.399$ & $0.012 \pm 0.388$ \\
\hline Visit 3 & $(n=52)$ & $(n=54)$ & $(\mathrm{n}=50)$ \\
\hline Mean \pm SD & $-0.361 \pm 0.504^{\dagger}$ & $-0.167 \pm 0.511$ & $-0.020 \pm 0.406$ \\
\hline Visit 4 & $(n=50)$ & $(n=54)$ & $(n=50)$ \\
\hline Mean \pm SD & $-0.343 \pm 0.484^{*, \dagger}$ & $-0.116 \pm 0.483$ & $-0.070 \pm 0.435$ \\
\hline
\end{tabular}

Notes: $* P<0.05$ vs ReSTOR $+3.0 ; * * P \leq 0.01$ vs ReSTOR $+3.0 ;{ }^{\dagger} P<0.02$ vs TECNIS Multifocal; †ip $<0.00$ I vs TECNIS Multifocal. ReSTOR (Bausch \& Lomb, Inc.; Rochester, NY, USA), TECNIS (Abbott Medical Optics, Inc.; Santa Ana, CA, USA), Crystalens AO (Bausch \& Lomb Inc.; Rochester, NY, USA).

Abbreviations: $n$, number of eyes; SD, standard deviation; $D$, diopter; MRSE, manifest refractive spherical equivalent; AO, Advanced Optics; vs, versus.

volume of accommodation. The Crystalens AO group had mean amplitude of accommodation of $1.60 \mathrm{D}$ at Visit 4.

\section{Uncorrected VA}

Monocular and binocular HC-UDVA, HC-UNVA, LC-UNVA, and monocular LC-UDVA showed no statistical significance among the three groups at Visit 4 (Figures 2 and 3A). The Crystalens AO group exhibited statistically significantly better binocular LC-UDVA than the TECNIS group at Visit 4 ( $P=0.016$, Figure 3B). The Crystalens AO group showed statistically significantly better binocular LC-UIVA than the ReSTOR and the TECNIS groups ( $P<0.001$, Figure $3 \mathrm{~B})$.

\section{Distance-corrected intermediate} and nearVA

For monocular and binocular HC-DCIVA, the Crystalens AO group performed statistically significantly better 


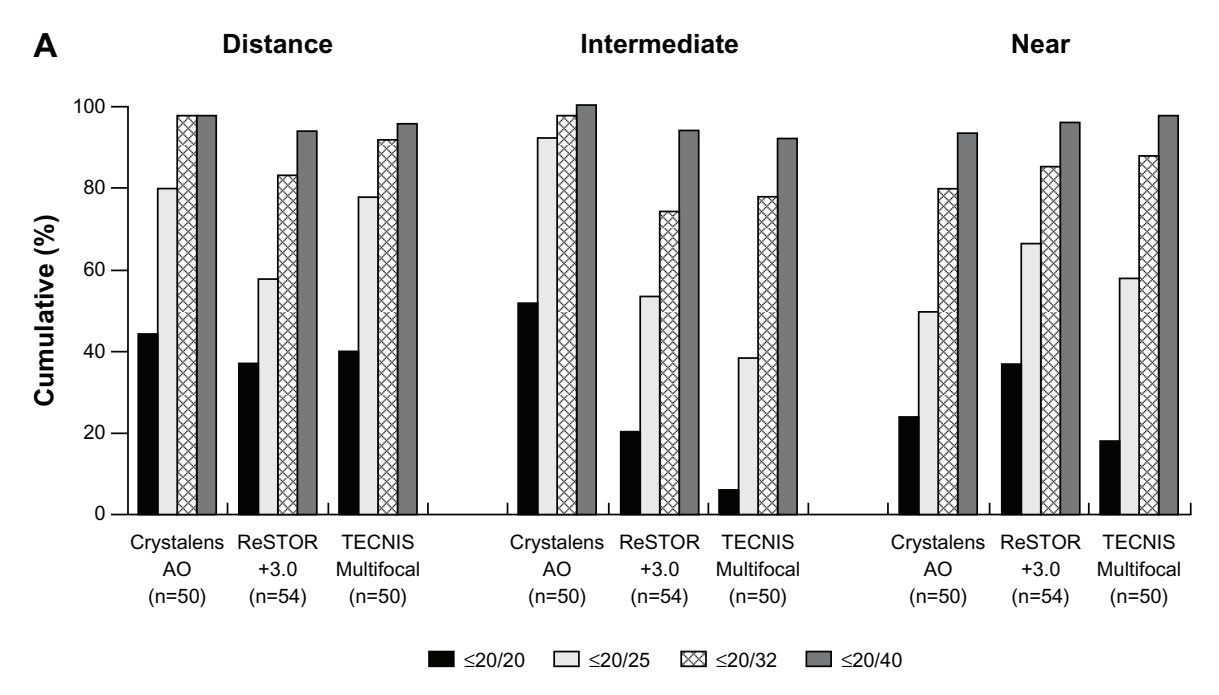

\begin{tabular}{|l|c|c|c|}
\hline \multicolumn{4}{|c|}{ Mean \pm SD logMAR (snellen) } \\
\hline & Crystalens AO & ReSTOR +3.0 & TECNIS Multifocal \\
\hline Monocular HC-UDVA & $0.076 \pm 0.099(20 / 23)$ & $0.130 \pm 0.138(20 / 26)$ & $0.091 \pm 0.105(20 / 24)$ \\
\hline Monocular HC-UIVA & $0.046 \pm 0.096(20 / 22)^{*}$ & $0.155 \pm 0.124(20 / 29)$ & $0.186 \pm 0.105(20 / 31)$ \\
\hline Monocular HC-UNVA & $0.152 \pm 0.123(20 / 28)$ & $0.107 \pm 0.130(20 / 26)$ & $0.130 \pm 0.110(20 / 27)$ \\
\hline
\end{tabular}

B Distance Intermediate Near

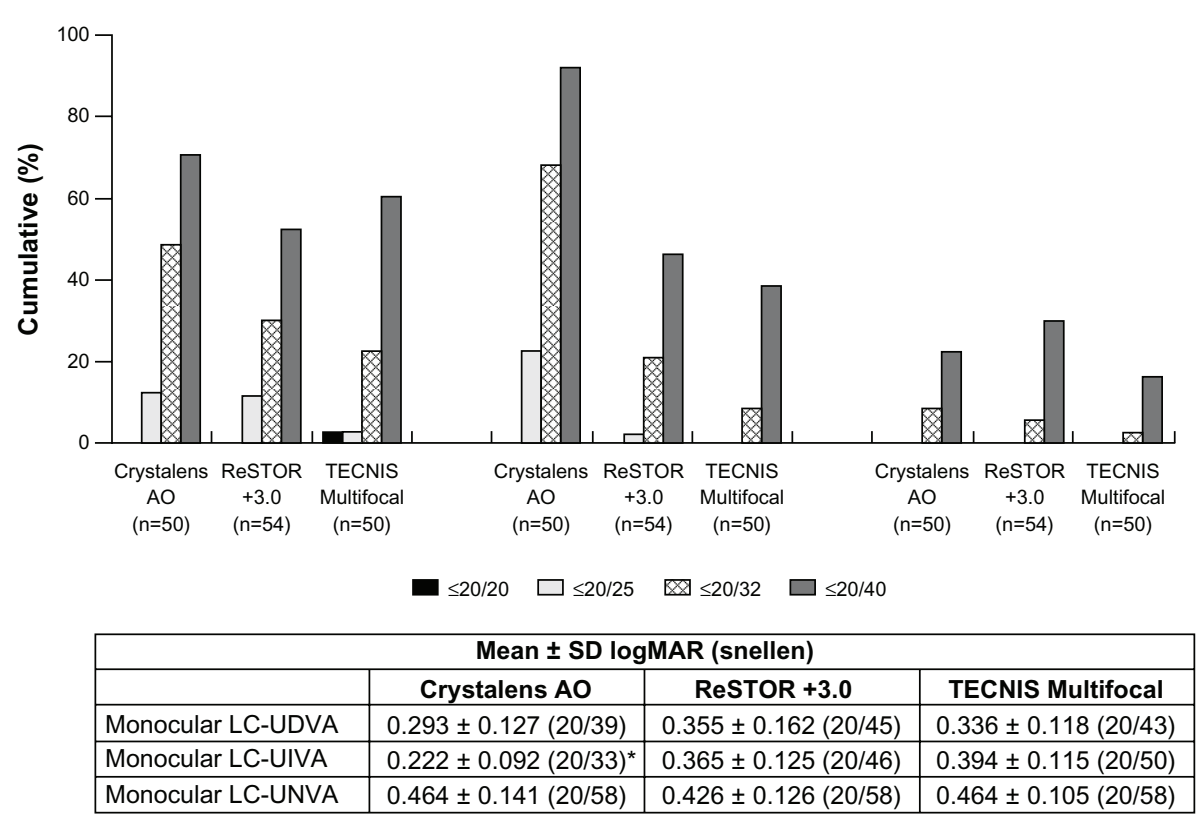

Figure 2 At Visit 4, (A) monocular high contrast uncorrected visual acuity at distance (HC-UDVA), intermediate (HC-UIVA), and near (HC-UNVA), and (B) monocular low contrast uncorrected visual acuity at distance (LC-UDVA), intermediate (LC-UIVA), and near (LC-UNVA).

Notes: $* P<0.001$ vs ReSTOR +3.0 and $P<0.001$ vs TECNIS Multifocal. ReSTOR (Alcon Laboratories, Inc.; Fort Worth, TX, USA ), TECNIS (Abbott Medical Optics, Inc.; Santa Ana, CA, USA), Crystalens AO (Bausch \& Lomb Inc.; Rochester, NY, USA).

Abbreviations: $n$, number of subjects; SD, standard deviation; AO, Advanced Optics; logMAR, logarithm of the minimum angle of resolution; vs, versus.

than the $\operatorname{ReSTOR}(P=0.003)$ and the TECNIS groups $(P<0.001$ and $P=0.002$, respectively) at Visit 4 (Figures 4A and 5A). For monocular and binocular HCDCNVA, the Crystalens AO group performed statistically significantly better than the TECNIS group $(P=0.003$ and $P=0.006$, respectively) and was not significantly different from the ReSTOR group at Visit 4 (Figures 4A and 5A).

For monocular (Figure 4B) and binocular (Figure 5B) LC-DCIVA and LC-DCNVA, the Crystalens AO group performed statistically significantly better than the ReSTOR $(P \leq 0.008)$ and the TECNIS $(P<0.001)$ groups at Visit 4. 


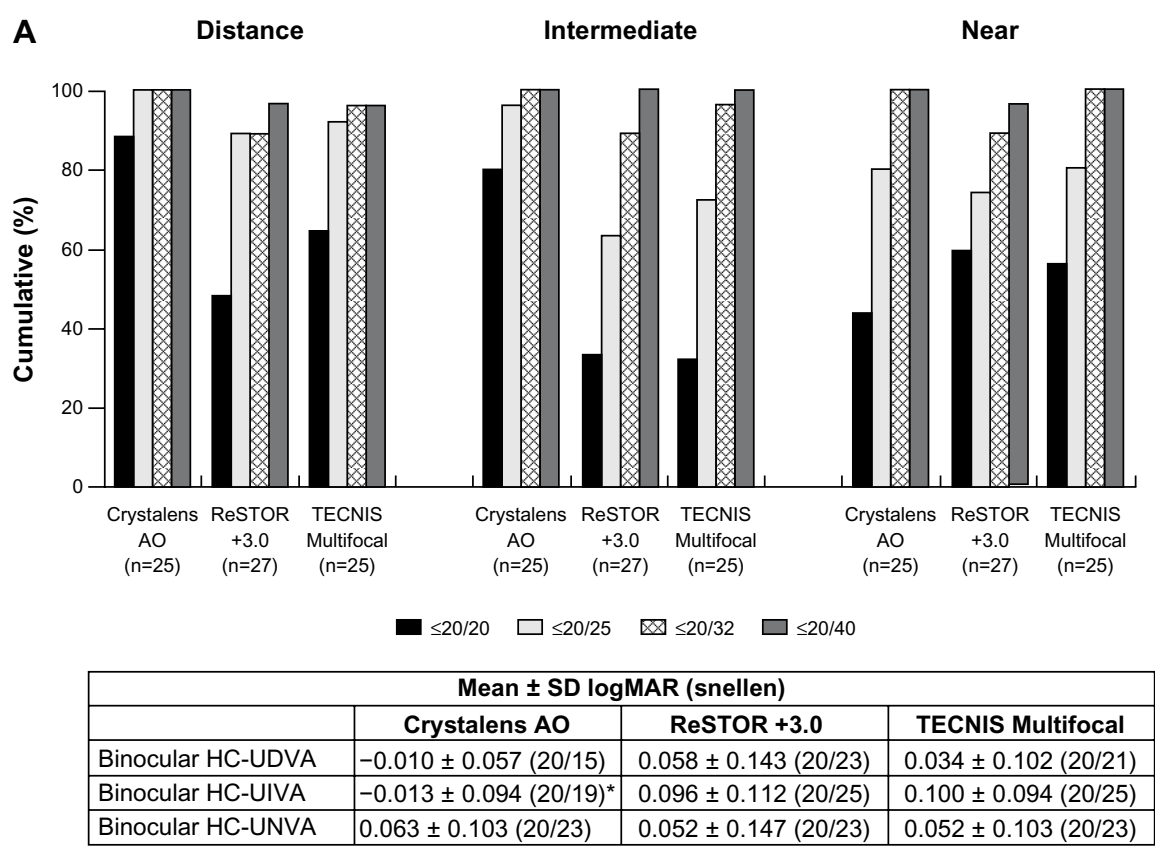

B

Distance

Intermediate

Near

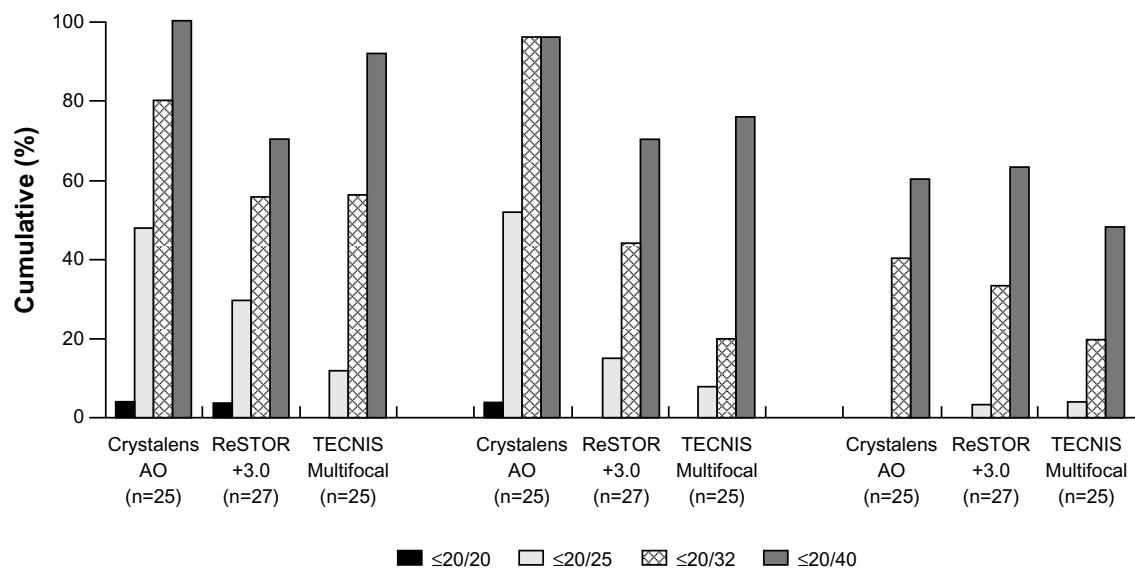

\begin{tabular}{|l|c|c|c|}
\hline \multicolumn{4}{|c|}{ Mean \pm SD logMAR (snellen) } \\
\hline & Crystalens AO & ReSTOR +3.0 & TECNIS Multifocal \\
\hline Binocular LC-UDVA & $0.178 \pm 0.078(20 / 24)^{\dagger}$ & $0.260 \pm 0.146(20 / 36)$ & $0.242 \pm 0.088(20 / 35)$ \\
\hline Binocular LC-UIVA & $0.150 \pm 0.067(20 / 28)^{\star}$ & $0.289 \pm 0.125(20 / 39)$ & $0.305 \pm 0.091(20 / 40)$ \\
\hline Binocular LC-UNVA & $0.326 \pm 0.115(20 / 42)$ & $0.347 \pm 0.143(20 / 44)$ & $0.349 \pm 0.113(20 / 45)$ \\
\hline
\end{tabular}

Figure 3 At Visit 4, (A) binocular high contrast uncorrected visual acuity at distance (HC-UDVA), intermediate (HC-UIVA), and near (HC-UNVA), and (B) binocular low contrast uncorrected visual acuity at distance (LC-UDVA), intermediate (LC-UIVA), and near (LC-UNVA).

Notes: $* P<0.001$ vs ReSTOR +3.0 and $P<0.00 I$ vs TECNIS Multifocal; ${ }^{+} P=0.016$ vs TECNIS Multifocal. ReSTOR (Bausch \& Lomb, Inc.; Rochester, NY, USA), TECNIS (Abbott Medical Optics, Inc.; Santa Ana, CA, USA), Crystalens AO (Bausch \& Lomb Inc.; Rochester, NY, USA).

Abbreviations: $n$, number of subjects; SD, standard deviation; AO, Advanced Optics; logMAR, logarithm of the minimum angle of resolution; vs, versus.

\section{Distance-corrected distance VA}

Monocular and binocular HC-CDVA were not significantly different between groups at Visit 4 (Figures 4A and 5A). Monocular and binocular LC-CDVA was statistically significantly worse for the ReSTOR and the TECNIS groups than that of the Crystalens AO group at Visit $4(P=0.026$ through $P=0.001$, Figures 4B and 5B).

\section{Mesopic contrast sensitivity without glare}

At Visit 4, monocular mesopic contrast sensitivity without glare in the Crystalens $\mathrm{AO}$ group was statistically significantly better than that of the TECNIS group at 1.5 cycles/degree $(P=0.046$, Figure 6A). At Visit 4, binocular mesopic contrast sensitivity without glare in the Crystalens $\mathrm{AO}$ group was statistically significantly better than that of the TECNIS group at 1.5 cycles/degree 

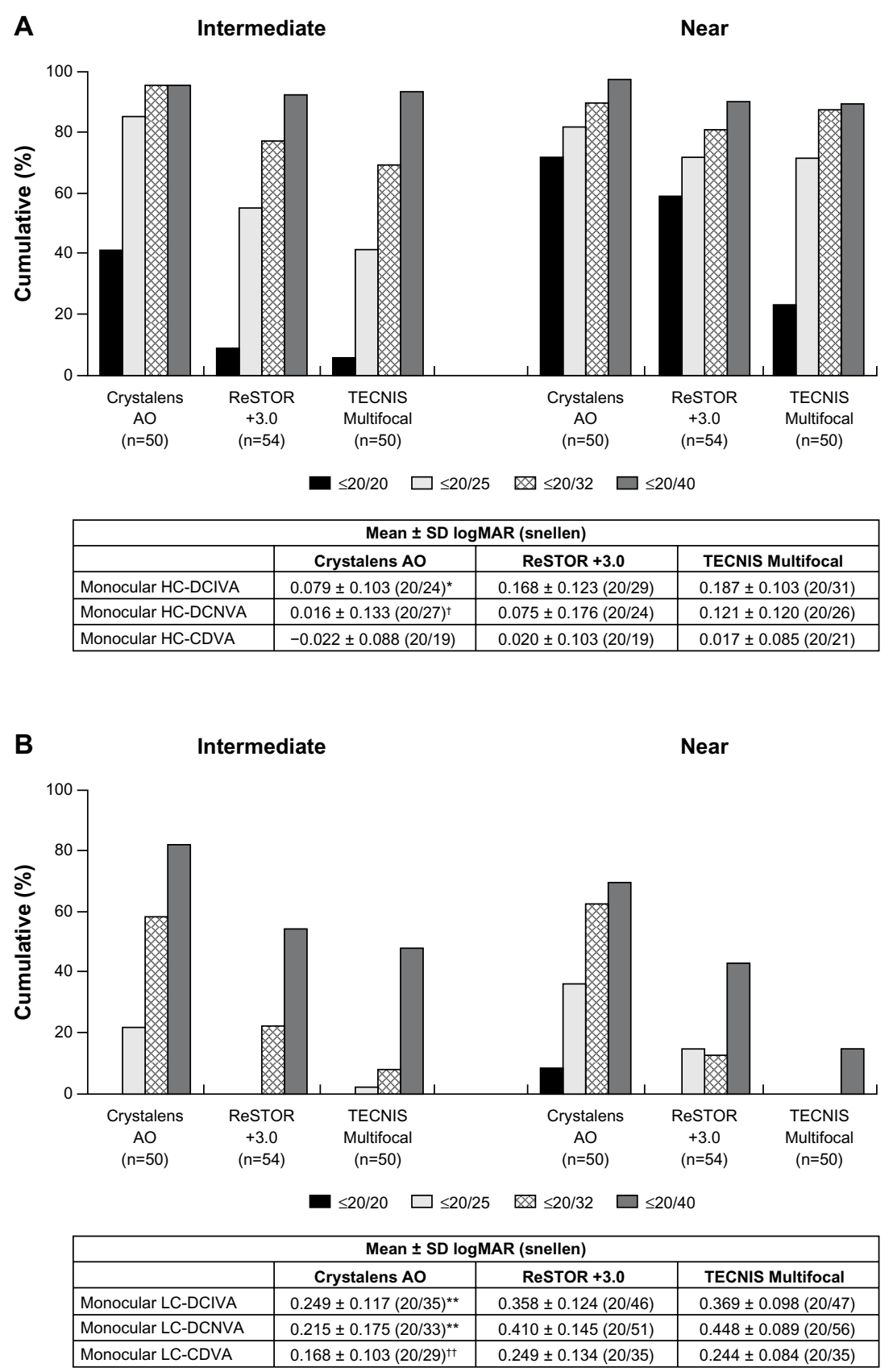

Figure 4 At Visit 4, (A) monocular high contrast distance-corrected visual acuity at distance (HC-CDVA), intermediate (HC-DCIVA) and near (HC-DCNVA), and (B) monocular low contrast distance-corrected visual acuity at distance (LC-CDVA), intermediate (LC-DCIVA) and near (LC-DCNVA).

Notes: ${ }^{*} P=0.003$ vs ReSTOR +3.0 and $P<0.00$ I vs TECNIS Multifocal; ${ }^{\dagger} P=0.003$ vs TECNIS Multifocal; $* * P<0.001$ vs ReSTOR +3.0 and $P<0.00$ I vs TECNIS Multifocal; ${ }_{t t} P=0.012$ vs ReSTOR +3.0 and $P<0.001$ vs TECNIS Multifocal. ReSTOR (Bausch \& Lomb, Inc.; Rochester, NY, USA), TECNIS (Abbott Medical Optics, Inc.; Santa Ana, CA, USA), Crystalens AO (Bausch \& Lomb Inc.; Rochester, NY, USA).

Abbreviations: $n$, number of subjects; SD, standard deviation; AO, Advanced Optics; logMAR, logarithm of the minimum angle of resolution; vs, versus.

$(P<0.001)$ and 3.0 cycles/degree $(P=0.046)$, and better than that of the ReSTOR group at 3.0 cycles/degree $(P=0.046$ ) (Figure 6B). The ReSTOR group was statistically significantly better than that of the TECNIS group at 1.5 cycles/degree $(P=0.010)$.

\section{Mesopic contrast sensitivity with glare}

The glare source had minimal effect on contrast sensitivity in all three groups. For the monocular and binocular assessments, contrast sensitivity with glare was slightly favorable for the Crystalens AO at Visit 4 (Figure 7A and B). Monocular mesopic contrast sensitivity with glare in Crystalens $\mathrm{AO}$ group was statistically significantly better than that for the TECNIS group at 3.0 cycles/degree $(P=0.025)$. Binocular mesopic contrast sensitivity with glare in the Crystalens AO group was statistically significantly better than that for the TECNIS group at 1.5 cycles/degree $(P=0.003)$. 
A

Intermediate

Near

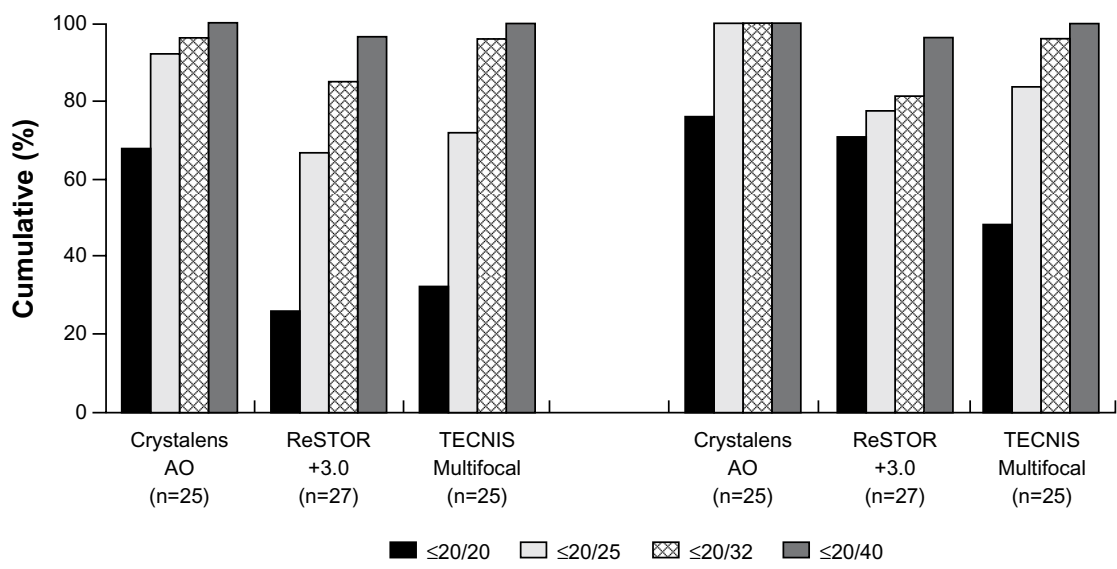

\begin{tabular}{|l|c|c|c|}
\hline \multicolumn{4}{|c|}{ Mean \pm SD logMAR (snellen) } \\
\hline & Crystalens AO & ReSTOR +3.0 & TECNIS Multifocal \\
\hline Binocular HC-DCIVA & $0.015 \pm 0.101(20 / 21)^{\star}$ & $0.115 \pm 0.122(20 / 26)$ & $0.105 \pm 0.082(20 / 25)$ \\
\hline Binocular HC-DCNVA & $-0.021 \pm 0.084(20 / 19)^{\dagger}$ & $0.027 \pm 0.176(20 / 21)$ & $0.066 \pm 0.104(20 / 23)$ \\
\hline Binocular HC-CDVA & $-0.067 \pm 0.067(20 / 17)$ & $-0.037 \pm 0.105(20 / 18)$ & $-0.033 \pm 0.069(20 / 19)$ \\
\hline
\end{tabular}

B Intermediate

Near

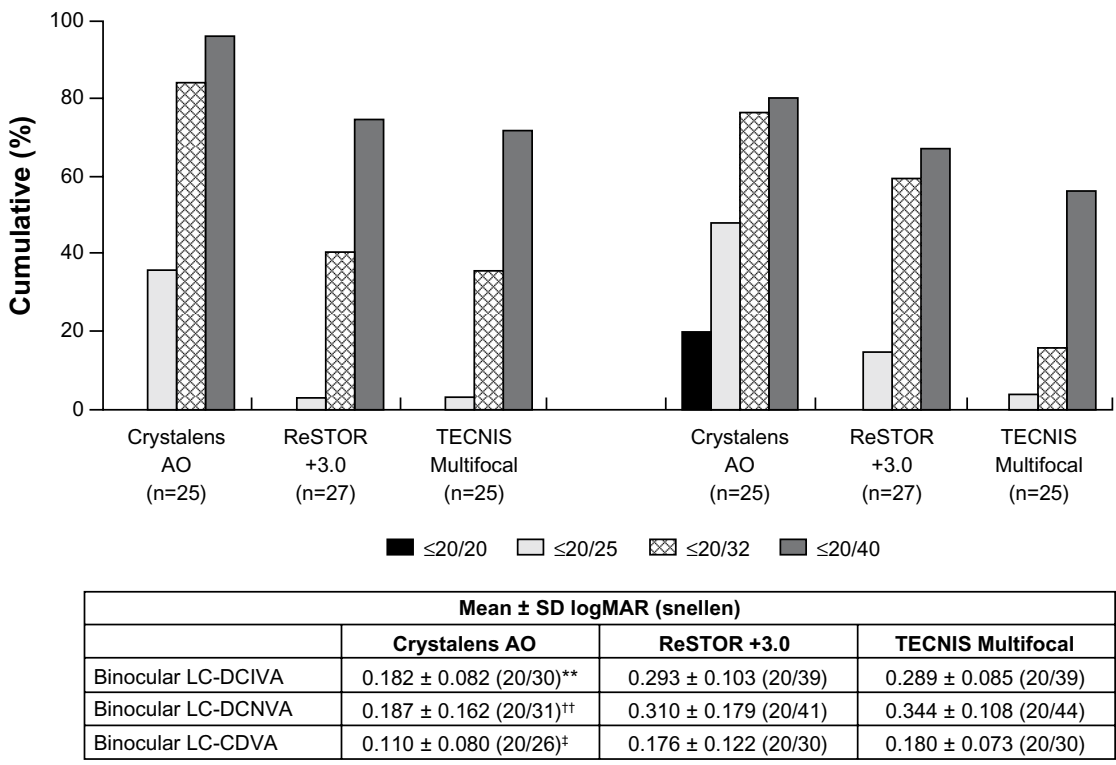

Figure 5 At Visit 4, (A) binocular high contrast distance-corrected visual acuity at distance (HC-CDVA), intermediate (HC-DCIVA) and near (HC-DCNVA), and (B) binocular low contrast distance-corrected visual acuity at distance (LC-CDVA), intermediate (LC-DCIVA) and near (LC-DCNVA).

Notes: $* P=0.003$ vs ReSTOR +3.0 and $P=0.002$ vs TECNIS Multifocal group; ${ }^{t} P=0.006$ vs TECNIS Multifocal; $* * P<0.001$ vs ReSTOR +3.0 and $P<0.001$ vs TECNIS Multifocal; $t+P=0.008$ vs ReSTOR +3.0 and $P<0.00$ I vs TECNIS Multifocal; $¥ P=0.026$ vs ReSTOR +3.0 and $P<0.002$ vs TECNIS Multifocal. ReSTOR (Bausch \& Lomb, Inc.; Rochester, NY, USA), TECNIS (Abbott Medical Optics, Inc.; Santa Ana, CA, USA), Crystalens AO (Bausch \& Lomb Inc.; Rochester, NY, USA).

Abbreviations: n, number of subjects; SD, standard deviation; AO, Advanced Optics; logMAR, logarithm of the minimum angle of resolution; vs, versus.

\section{Halos and starbursts}

Tables 2 and 3 show the occurrence of halos and starbursts. Monocular and binocular assessments demonstrated that there were statistically significantly fewer halos and starbursts for the Crystalens AO group compared to both the ReSTOR $(P<0.001)$ and the TECNIS $(P<0.001)$ groups at Visit 4.

\section{Safety}

The rate of FDA-defined cumulative and persistent adverse events (AEs) through Visit 4 were at or below the FDA rate of historical control. Ocular AEs were of the type and frequency typically seen in subjects who had had cataract surgery. All three lenses met all clinical safety endpoints in slit lamp findings, IOP, color test, and binocular depth perception. 


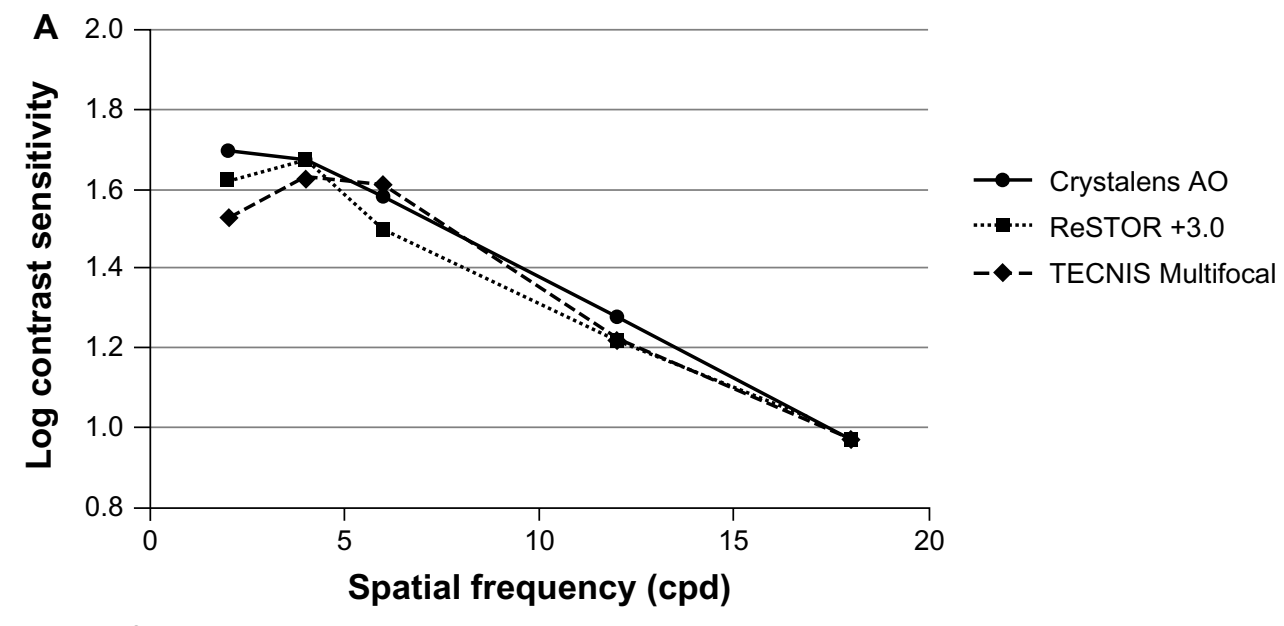

$P$ values for comparisons between groups

\begin{tabular}{|l|c|c|c|c|c|}
\hline & \multicolumn{5}{|c|}{ Spatial frequencies (cpd) } \\
\hline Comparison & $\mathbf{1 . 5}$ & $\mathbf{3 . 0}$ & $\mathbf{6 . 0}$ & $\mathbf{1 2 . 0}$ & $\mathbf{1 8 . 0}$ \\
\hline Crystalens AO vs ReSTOR +3.0 & $>0.999$ & $>0.999$ & $>0.999$ & $>0.999$ & $>0.999$ \\
\hline Crystalens AO vs TECNIS Multifocal & 0.046 & $>0.999$ & $>0.999$ & $>0.999$ & $>0.999$ \\
\hline ReSTOR +3.0 vs TECNIS Multifocal & 0.088 & 0.483 & 0.067 & 0.804 & 0.938 \\
\hline
\end{tabular}

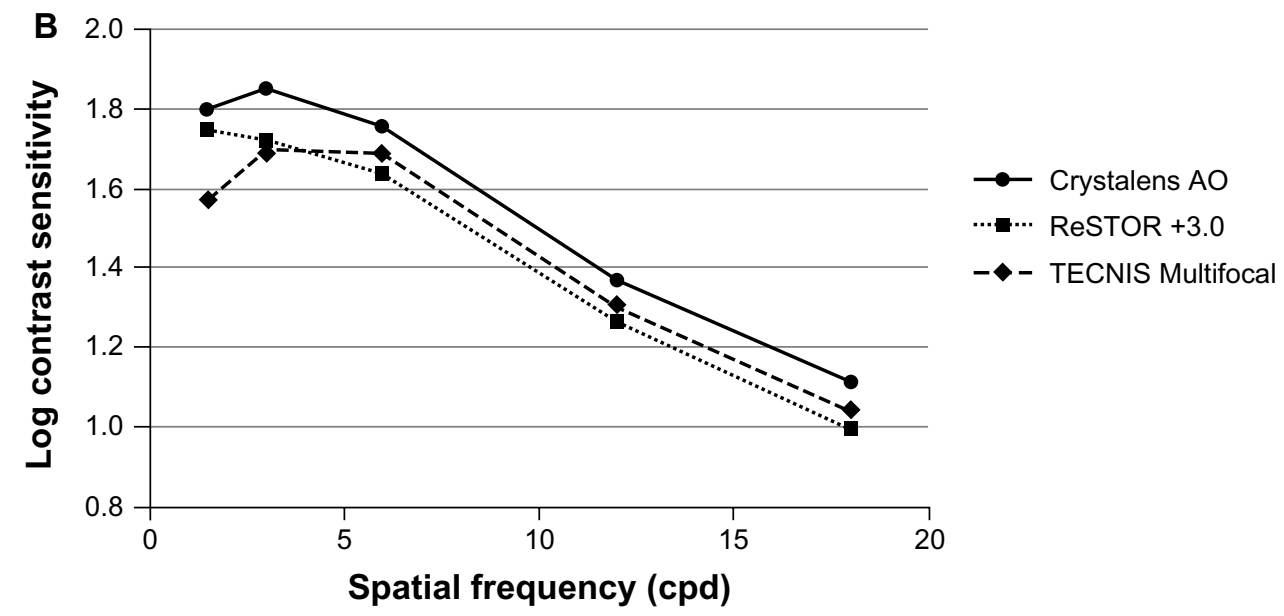

$P$ values for comparisons between groups

\begin{tabular}{|l|c|c|c|c|c|}
\hline & \multicolumn{5}{|c|}{ Spatial frequencies (cpd) } \\
\hline Comparison & $\mathbf{1 . 5}$ & $\mathbf{3 . 0}$ & $\mathbf{6 . 0}$ & $\mathbf{1 2 . 0}$ & $\mathbf{1 8 . 0}$ \\
\hline Crystalens AO vs ReSTOR +3.0 & 0.676 & 0.046 & 0.090 & 0.253 & 0.222 \\
\hline Crystalens AO vs TECNIS Multifocal & $<0.001$ & 0.009 & 0.316 & 0.395 & 0.741 \\
\hline ReSTOR +3.0 vs TECNIS Multifocal & 0.010 & 0.613 & 0.500 & 0.762 & 0.700 \\
\hline
\end{tabular}

Figure 6 Monocular (A) and binocular (B) mesopic contrast sensitivity without glare at five spatial frequencies at Visit 4.

Notes: ReSTOR (Bausch \& Lomb, Inc.; Rochester, NY, USA), TECNIS (Abbott Medical Optics, Inc.; Santa Ana, CA, USA), Crystalens AO (Bausch \& Lomb Inc.; Rochester, NY, USA).

Abbreviations: AO, Advanced Optics; vs, versus.

\section{Discussion}

To our knowledge, this is the first study to compare the clinical outcomes achieved with the Crystalens AO, ReSTOR, and TECNIS IOLs. As expected, based on the technology of the accommodating lens, the Crystalens AO group had significantly better monocular and binocular, HC-UIVA, LC-UIVA, HC-DCIVA, and LC-DCIVA, and significantly fewer monocular and binocular halos and starbursts than the ReSTOR and the TECNIS groups.

According to labeling and historical data, the Crystalens AO IOL is designed to provide approximately $1 \mathrm{D}$ of accommodation; therefore, the lens would be expected to achieve DCNVA of 20/40 through 20/60. ${ }^{3,10}$ The present data show that the Crystalens AO group exhibited a mean 


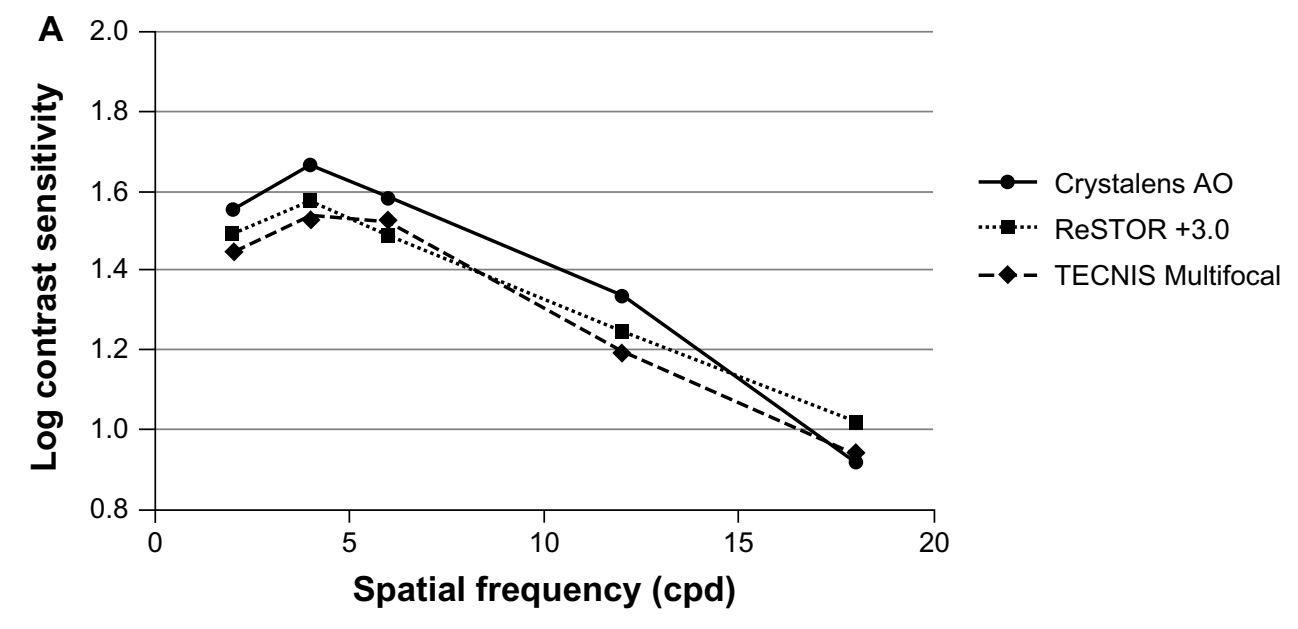

$P$ values for comparisons between groups

\begin{tabular}{|l|c|c|c|c|c|}
\hline & \multicolumn{5}{|c|}{ Spatial frequencies (cpd) } \\
\hline Comparison & $\mathbf{1 . 5}$ & $\mathbf{3 . 0}$ & $\mathbf{6 . 0}$ & $\mathbf{1 2 . 0}$ & $\mathbf{1 8 . 0}$ \\
\hline Crystalens AO vs ReSTOR +3.0 & 0.324 & 0.163 & 0.269 & 0.237 & 0.646 \\
\hline Crystalens AO vs TECNIS Multifocal & 0.102 & 0.025 & 0.325 & 0.094 & 0.836 \\
\hline ReSTOR +3.0 vs TECNIS Multifocal & 0.507 & 0.507 & 0.869 & 0.652 & 0.792 \\
\hline
\end{tabular}

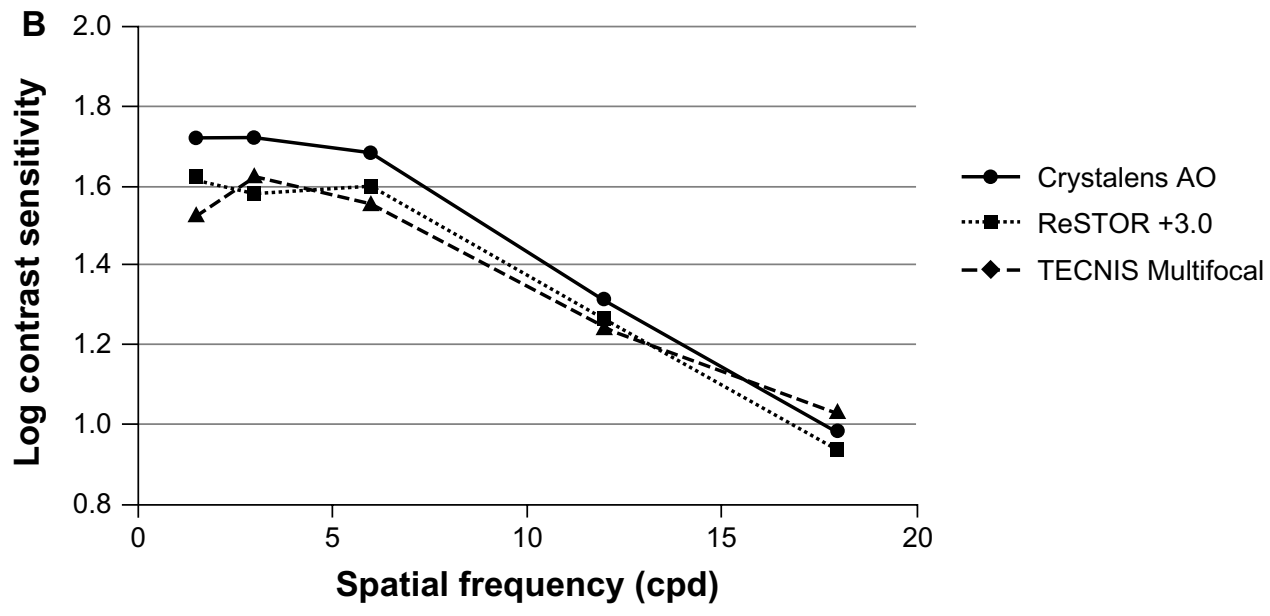

$P$ values for comparisons between groups

\begin{tabular}{|l|c|c|c|c|c|}
\hline & \multicolumn{5}{|c|}{ Spatial frequencies (cpd) } \\
\hline Comparison & $\mathbf{1 . 5}$ & $\mathbf{3 . 0}$ & $\mathbf{6 . 0}$ & $\mathbf{1 2 . 0}$ & $\mathbf{1 8 . 0}$ \\
\hline Crystalens AO vs ReSTOR +3.0 & 0.123 & 0.076 & 0.254 & 0.600 & 0.551 \\
\hline Crystalens AO vs TECNIS Multifocal & 0.003 & 0.147 & 0.180 & 0.447 & $>0.999$ \\
\hline ReSTOR +3.0 vs TECNIS Multifocal & 0.196 & 0.569 & 0.678 & 0.833 & 0.636 \\
\hline
\end{tabular}

Figure 7 Monocular (A) and binocular (B) mesopic contrast sensitivity with glare at five spatial frequencies at Visit 4.

Notes: ReSTOR (Bausch \& Lomb, Inc.; Rochester, NY, USA), TECNIS (Abbott Medical Optics, Inc.; Santa Ana, CA, USA), Crystalens AO (Bausch \& Lomb Inc.; Rochester, NY, USA).

Abbreviations: AO, Advanced Optics; vs, versus.

accommodative amplitude of $1.60 \mathrm{D}$ and HC-DCNVA of 20/21. Monocular and binocular, HC-UNVA, LC-UNVA, HC-DCNVA, and LC-DCNVA showed no differences among the three IOLs at Visit 4 . The VAs for ReSTOR and TECNIS groups were similar to or better than previously reported. ${ }^{15,16}$ The combination of $1.60 \mathrm{D}$ of objective accommodative amplitude with the approximate measurement of $-0.34 \mathrm{D}$ of mean MRSE for the Crystalens AO group coincides with approximately $2.00 \mathrm{D}$ of potential near addition at the corneal plane. The ReSTOR provides approximately $2.10 \mathrm{D}$ of near addition at the corneal plane; which explains the similar near vision results for these two platforms. With regard to the TECNIS, which provides 2.80 D of near correction at the corneal plane, the similarities between cohorts may be attributed to the distance of the near vision measurement, which was taken at $40 \mathrm{~cm}$ versus the 
Table 2 Incidence and distribution of monocular halos and starbursts at Visit 4

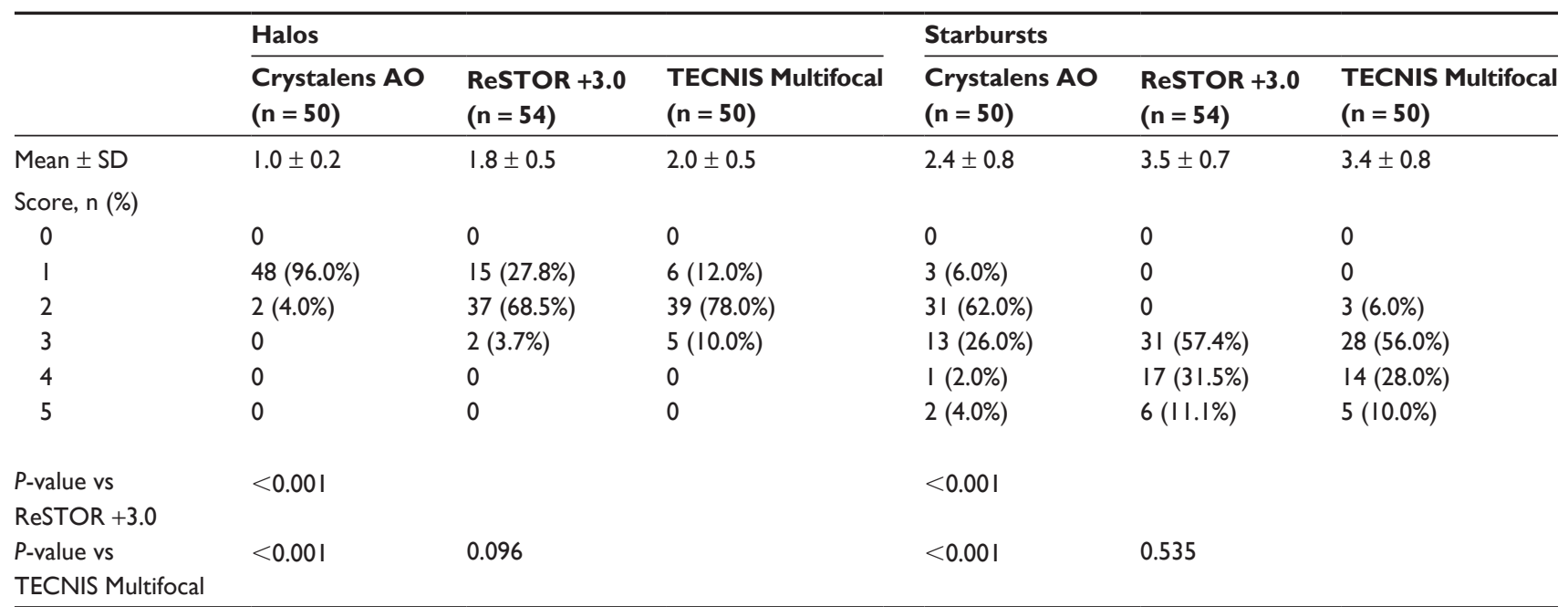

Notes: Subject-reported halos and starbursts were measured on 5-point integer scales, with the scale of I-5 translating to minimum, moderate, extensive. ReSTOR (Bausch \& Lomb, Inc.; Rochester, NY, USA), TECNIS (Abbott Medical Optics, Inc.; Santa Ana, CA, USA), Crystalens AO (Bausch \& Lomb Inc.; Rochester, NY, USA).

Abbreviations: n, number of subjects; AO, Advanced Optics; SD, standard deviation; vs, versus.

optimal distance of $33 \mathrm{~cm}$ for the TECNIS IOL. ${ }^{12}$ Therefore, the results were expected from theoretical-based optics. The Crystalens AO data are comparable to recently published pilot data. ${ }^{17}$

The excellent outcomes in the present study with all three lenses may be attributed to diligent capsule polish, cortical clean-up, targeting, biometry, and capsulorhexis, and assurance that the accommodating lens was vaulted in the posterior position to optimize arching and/or translational movement. In addition, instilling a tapering course of anti-inflammatory agents prevented early aggressive capsular contraction that could impact IOL positioning or the potential for the Crystalens to accommodate to achieve the optimal amplitude. Meticulous surgical technique is paramount for optimal results with all IOLs.

Because there can be variance between the targeted and achieved refractive outcomes, assessing the outcome of the first eye provides an opportunity to refine target for the second eye. In this study, the eye with greater blur was operated on first, regardless of dominance. At the 1-week follow-up, refraction of the first eye was measured prior to determining IOL power for the second eye. In the ReSTOR and the TECNIS groups, if the first eye was off target, IOL power that would compensate for the degree of ametropia was selected for the second eye, and emmetropia in the second eye was usually achieved. For the Crystalens AO group, the

Table 3 Incidence and distribution of binocular halos and starbursts at Visit 4

\begin{tabular}{|c|c|c|c|c|c|c|}
\hline & \multicolumn{3}{|l|}{ Halos } & \multicolumn{3}{|l|}{ Starbursts } \\
\hline & $\begin{array}{l}\text { Crystalens AO } \\
(n=25)\end{array}$ & $\begin{array}{l}\text { ReSTOR +3.0 } \\
(n=27)\end{array}$ & $\begin{array}{l}\text { TECNIS Multifocal } \\
(n=25)\end{array}$ & $\begin{array}{l}\text { Crystalens AO } \\
(n=25)\end{array}$ & $\begin{array}{l}\text { ReSTOR +3.0 } \\
(n=27)\end{array}$ & $\begin{array}{l}\text { TECNIS Multifocal } \\
(n=25)\end{array}$ \\
\hline Mean \pm SD & $1.0 \pm 0.2$ & $1.8 \pm 0.5$ & $1.9 \pm 0.5$ & $2.3 \pm 0.8$ & $3.5 \pm 0.7$ & $3.3 \pm 0.6$ \\
\hline \multicolumn{7}{|l|}{ Score, n (\%) } \\
\hline 0 & 0 & 0 & 0 & 0 & 0 & 0 \\
\hline 1 & 24 (96.0\%) & 7 (25.9\%) & $4(16.0 \%)$ & 2 (8.0\%) & 0 & 0 \\
\hline 2 & I (4.0\%) & 19 (70.4\%) & 19 (76.0\%) & 15 (60.0\%) & 0 & I (4.0\%) \\
\hline 3 & 0 & I (3.7\%) & $2(8.0 \%)$ & 7 (28.0\%) & I6 (59.3\%) & 17 (68.0\%) \\
\hline 4 & 0 & 0 & 0 & 0 & $8(29.6 \%)$ & $6(24.0 \%)$ \\
\hline 5 & 0 & 0 & 0 & I (4.0\%) & 3 (II.1\%) & I (4.0\%) \\
\hline $\begin{array}{l}P \text {-value vs } \\
\text { ReSTOR }+3.0\end{array}$ & $<0.001$ & & & $<0.001$ & & \\
\hline $\begin{array}{l}P \text {-value vs } \\
\text { TECNIS Multifocal }\end{array}$ & $<0.001$ & 0.315 & & $<0.001$ & 0.232 & \\
\hline
\end{tabular}

Notes: Subject-reported halos and starbursts were measured on 5-point integer scales, with the scale of I-5 translating to minimum, moderate, extensive. ReSTOR (Bausch \& Lomb, Inc.; Rochester, NY, USA), TECNIS (Abbott Medical Optics, Inc.; Santa Ana, CA, USA), Crystalens AO (Bausch \& Lomb Inc.; Rochester, NY, USA). Abbreviations: $n$, number of subjects; AO, Advanced Optics; SD, standard deviation; vs, versus. 
second eye was targeted to $-0.50 \mathrm{D}$, regardless of dominance. However, if the first eye with the Crystalens AO was at least $-0.50 \mathrm{D}$ myopic, the IOL power of the second eye was selected to achieve a plano or mildly hyperopic outcome. Based on previous experience, slight myopia was targeted for the Crystalens AO to enhance uncorrected near vision. It is believed that this approach is responsible for optimal binocular near vision in the Crystalens AO group. Other researchers have suggested that near vision in the accommodating lens could be the result of dynamic changes in spherical aberration and other higher order aberrations, which occur via movement of the lens and changes in vitreous pressure. ${ }^{1,18,19}$ Another possibility may be related to a secondary mechanism such as optic flexure, or accommodative arching, which causes the lens to change shape as it moves along the axis, enabling subjects to see better than predicted. ${ }^{20}$ Outcomes of the ReSTOR and the TECNIS groups were not statistically different, mainly due to targeting of refractive outcomes, which was based on surgeon experience and recommendations of the manufacturers. Further, the mean targeted postoperative MRSEs in all groups were achieved, refractive predictability between the groups was similar, and refractions remained stable over all visits.

It was anticipated that the Crystalens AO group would have better contrast sensitivity compared with the multifocal IOL groups. ${ }^{1,3,21}$ However, in this study the Crystalens AO group only had significantly better contrast sensitivity at lower spatial frequencies. This finding cannot be explained, especially because the Crystalens AO group had better binocular intermediate and distance VA under low contrast conditions, which supports the premise that the IOL produces better contrast sensitivity.

The study has some limitations. The follow-up period of 180 days was longer than that of many studies; however, data beyond 180 days is needed. Also, subjects with potential for poor outcomes were excluded. Therefore, in the general population the outcomes could be somewhat worse for all three IOLs. The percentage of spectacle independence or the types of spectacles required (for near or distance vision) were not evaluated, and subject satisfaction could not be rigorously assessed. Satisfaction could not be adequately assessed because the study was randomized and not customized to individual subject needs. The subjects were not promised spectacle independence, optimal contrast sensitivity, or absence of undesirable photic phenomena; so satisfaction with the outcome could not be ascertained.

This was a single-center, single-surgeon study. This is a study design advantage because the procedures were highly standardized. On the other hand, the study was only partially masked because the IOLs and insertion devices are obviously different. The advantage of randomization is that the study did not match IOLs with lifestyle, visual needs, outcome expectations, or "best case." Therefore, testing was not biased by preconceived expectations. This randomization supports rigor of methodology and reporting. Nonetheless, repeating this study with a multicenter design would be beneficial to support the present conclusions. Also, it would be beneficial for future studies to include a monofocal control group.

\section{Conclusion}

In conclusion, all three IOLs had excellent uncorrected acuity results at all distances and had good safety profile, which confirms the previously established safety and effectiveness of these IOLs. Having near plano refractive outcome in at least one eye gave the three groups similarly favorable UDVA and reinforced the importance of personalized A-constants. The multifocal IOLs were expected to be at disadvantage in low-contrast UDVA, but LC-UDVA was comparable between groups because Crystalens AO was targeted for slight myopia. For LC-CDVA, where influence of refractive error was removed, the Crystalens AO outperformed multifocal lenses. The results show that the Crystalens AO provided similar near vision outcomes, statistically fewer halos and starbursts, and significantly better intermediate vision. Taken together, the data can help guide surgeons and subjects in making informed choices when choosing the optimal IOL for their needs.

\section{Acknowledgments}

This study was sponsored by Bausch \& Lomb Inc., Rochester, NY, USA. Writing assistance was provided by Heather S Oliff, PhD (Science Consulting Group LLC, North Tustin, CA, USA), statistical analysis by Gary Mosehauer, MS (Bausch \& Lomb), and data analysis by Michael Sowards (Bausch \& Lomb).

\section{Disclosure}

Dr Ang received an honorarium and travel support. The authors report no other conflicts of interest in this work.

\section{References}

1. Cumming JS, Colvard DM, Dell SJ, et al. Clinical evaluation of the Crystalens AT-45 accommodating intraocular lens: results of the US Food and Drug Administration clinical trial. J Cataract Refract Surg. 2006;32(5):812-825.

2. Legeais JM, Werner L, Werner L, Abenhaim A, Renard G. Pseudoaccommodation: BioComFold versus a foldable silicone intraocular lens. J Cataract Refract Surg. 1999;25(2):262-267. 
3. Alio JL, Plaza-Puche AB, Montalban R, Javaloy J. Visual outcomes with a single-optic accommodating intraocular lens and a low-addition-power rotational asymmetric multifocal intraocular lens. J Cataract Refract Surg. 2012;38(6):978-985.

4. Pepose JS, Qazi MA, Davies J, et al. Visual performance of patients with bilateral vs combination Crystalens, ReZoom, and ReSTOR intraocular lens implants. Am J Ophthalmol. 2007;144(3):347-357.

5. Mathen MM. Multifocal IOL- An overview. Kerala J Ophthalmol. 2010;22(1):24-29.

6. Pepose JS, Wang D, Altmann GE. Comparison of through-focus image sharpness across five presbyopia-correcting intraocular lenses. Am J Ophthalmol. 2012;154(1):20-28. e21.

7. Alfonso JF, Fernandez-Vega L, Baamonde MB, Montes-Mico R. Prospective visual evaluation of apodized diffractive intraocular lenses. J Cataract Refract Surg. 2007;33(7):1235-1243.

8. Montes-Mico R, Alio JL. Distance and near contrast sensitivity function after multifocal intraocular lens implantation. J Cataract Refract Surg. 2003;29(4):703-711.

9. Pepose JS. The longevity revolution. Reviewing the impact of increasing lifespan on the choice of lifestyle-enhancing intraocular lenses. Ophthal Managment. 2011;August(Suppl):3-7.

10. Crystalens accommodating posterior chamber intraocular lens Physician Labeling. Aliso Viejo, CA: Bausch and Lomb Inc; 2012.

11. Alcon AcrySof IQ ReSTOR intraocular lens (IOL) patient information brochure: Alcon Inc; 2008.

12. Tecnis Multifocal 1-Piece Intraocular Lens (IOL) package insert. Santa Ana, CA: Abbott Medical Optics Inc; 2012.

13. Retzlaff JA, Sanders DR, Kraff MC. Development of the SRK/T intraocular lens implant power calculation formula. J Cataract Refract Surg. 1990;16(3):333-340.
14. International Organization for Standardization. ISO 11979-7: 2006(E) Ophthalmic Implants - Intraocular lenses - Part 7: Clinical investigations; 2006.

15. Cochener B, Lafuma A, Khoshnood B, Courouve L, Berdeaux G. Comparison of outcomes with multifocal intraocular lenses: a meta-analysis. Clin Ophthalmol. 2011;5:45-56.

16. Gierek-Ciaciura S, Cwalina L, Bednarski L, Mrukwa-Kominek E. A comparative clinical study of the visual results between three types of multifocal lenses. Graefes Arch Clin Exp Ophthalmol. 2010;248(1):133-140.

17. Szigeti A, Kranitz K, Takacs AI, Mihaltz K, Knorz MC, Nagy ZZ. Comparison of long-term visual outcome and IOL position with a single-optic accommodating IOL after 5.5- or $6.0-\mathrm{mm}$ femtosecond laser capsulotomy. J Refract Surg. 2012;28(9):609-613.

18. Macsai MS, Padnick-Silver L, Fontes BM. Visual outcomes after accommodating intraocular lens implantation. $J$ Cataract Refract Surg. 2006;32(4):628-633.

19. Pepose JS, Wang D, Altmann GE. Comparison of through-focus image quality across five presbyopia-correcting intraocular lenses (an American Ophthalmological Society thesis). Trans Am Ophthalmol Soc. 2011;109:221-231.

20. Waltz K. The Crystalens changes its radius of curvature. Cataract Refract Surg Today. 2005; June:66-68. Available from: http://bmctoday.net/crstoday/2005/06/article.asp?f=CRST0605_14.php. Accessed August 6, 2013.

21. Pepose JS, Qazi MA, Edwards KH, Sanderson JP, Sarver EJ. Comparison of contrast sensitivity, depth of field and ocular wavefront aberrations in eyes with an IOL with zero versus positive spherical aberration. Graefes Arch Clin Exp Ophthalmol. 2009;247(7):965-973.
Clinical Ophthalmology

\section{Publish your work in this journal}

Clinical Ophthalmology is an international, peer-reviewed journal covering all subspecialties within ophthalmology. Key topics include: Optometry; Visual science; Pharmacology and drug therapy in eye diseases; Basic Sciences; Primary and Secondary eye care; Patient Safety and Quality of Care Improvements. This journal is indexed on

Submit your manuscript here: http://www.dovepress.com/clinical-ophthalmology-journal

\section{Dovepress}

PubMed Central and CAS, and is the official journal of The Society of Clinical Ophthalmology (SCO). The manuscript management system is completely online and includes a very quick and fair peer-review system, which is all easy to use. Visit http://www.dovepress.com/ testimonials.php to read real quotes from published authors. 